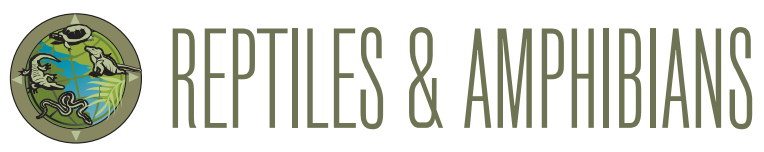

\title{
Cannibalism in the Kachin Smooth Gecko, Hemidactylus aquilonius Zug and McMahan 2007 (Squamata: Gekkonidae), from Assam, India
}

\author{
Sachin Ranade ${ }^{1}$ and Jayaditya Purkayastha ${ }^{2}$
}

${ }^{1}$ Vulture Conservation Breeding Centre, Belguri Village, Rani, Kamrup District 781131, Assam, India (s.ranade@bnhs.org [corresponding author]) ${ }^{2}$ Help Earth, Raghunath Choudhury Path, Lachitnagar, Guwahati 781007, Assam, India (mail.jayaditya@gmail.com)

$\mathrm{C}$ annibalism is not uncommon and has been reported in organisms ranging from protozoans to mammals (Fox 1975). Polis and Myers (1985) noted that cannibalism in amphibians and reptiles can be ecologically important for many species and can strongly influence competitive interactions and life histories of populations. The frequency of cannibalism in any population is influenced by the age, size, sex, and density of conspecifics, degree of relatedness, and available food (Fox 1975; Polis 1981). Polis and Myers (1985) and Mitchell (1986) compiled records of cannibalism in 49 and 191 species of reptiles, respectively (note that the former also included records of conspecific oophagy). However, relatively few species in either account were geckos. More recent accounts of cannibalism by geckos include the Common Leopard Gecko (Eublepharis macularius) (Bonke et al. 2011), Northern House Gecko (Hemidactylus flaviviridis) (Polis and Myers 1985), Tropical House Gecko (Hemidactylus mabouia) (Lyakurwa 2017), and Spotted House Gecko (Hemidactylus parvimaculatus) (Dissanayake 2017). Herein, we report cannibalism in the Kachin Smooth Gecko (Hemidactylus aquilonius) from Rani, Assam, India.

At 1642 h on 12 August 2020, we heard a faint "chirrup" at the Vulture Conservation Breeding Center, Rani, Assam, India $(26.0003 \mathrm{~N}, 91.5483 \mathrm{E})$ and subsequently saw an adult $H$. aquilonius with a conspecific juvenile in its grasp (Fig. 1). When the adult adjusted its grip, the juvenile bit its lower jaw, but to no avail. The larger gecko carried its prey to a nearby shutter and swallowed it headfirst. Ingestion was completed at $1649 \mathrm{~h}$.

\section{Literature Cited}

Bonke, R., W. Böhme, K. Opiela, and D. Rödder. 2011. A remarkable case of cannibalism in juvenile Leopard Geckos, Eublepharis macularius (Blyth, 1854) (Squamata: Eublepharidae). Herpetology Notes 4: 211-212.

Dissanayake, D.B. 2017. Hemidactylus parvimaculatus (Sri Lankan Spotted House Gecko). Cannibalism. Herpetological Review 48: 647.

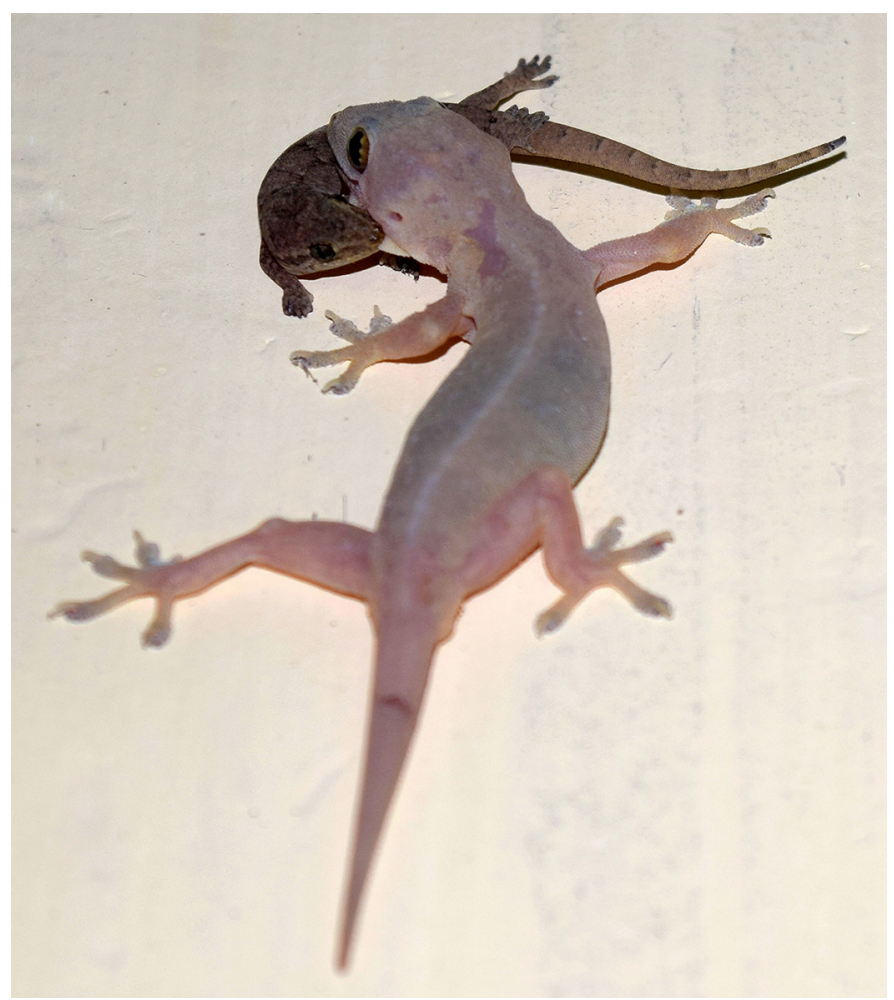

Fig. 1. Cannibalism in Kachin Smooth Geckos (Hemidactylus aquilonius) in Rani, Assam, India. Photograph by Sachin Ranade.

Fox, L.R. 1975. Cannibalism in natural populations. Annual Review of Ecology, Evolution, and Systematics 6: 87-106.

Lyakurwa, J.V. 2017. Hemidactylus mabouia (Tropical House Gecko). Cannibalism. Herpetological Review 48: 646.

Mitchell, J.C. 1986. Cannibalism in reptiles: A worldwide review. SSAR Herpetological Circular 15: 1-37.

Polis, G.A. 1981. The evolution and dynamics of intraspecific predation. Annual Review of Ecology, Evolution, and Systematics 12: 225-251.

Polis, G.A. and C.A. Myers. 1985. A survey of intraspecific predation among reptiles and amphibians. Journal of Herpetology 19: 99-107. 